\title{
16
}

\section{Conceptual Role Accounts of Meaning in Metaethics}

\author{
Matthew Chrisman
}

\section{INTRODUCTION}

Metaethicists are interested in questions in the philosophy of language as these apply to ethical and more generally normative terms. One of the core questions in the philosophy of language is how to explain the meaning of terms and the sentences in which they figure. Hence, an important question in metaethics is how to explain the meaning of ethical terms and the sentences in which they figure. In the philosophy of language, one of the main accounts of meaning stresses the roles terms play in an interconnected web of meanings central to our linguistic practice of talking about the world and what to do in it. This general view of meaning is sometimes dubbed "conceptual role semantics." The basic idea is that the meaning of a term is not something it has, independent of conceptual connections to other words and sentences, but rather something determined by these very connections.

The label "conceptual role semantics" misleadingly suggests that the view is a competitor to standard approaches to model theoretic semantics (such as possible worlds semantics) as an attempt to model the way the meaning of whole sentences in particular languages could be a systematic function of the meaning of their parts and their logical forms. Although the issue is somewhat controversial, as I see things, the conceptual role view is best pursued instead as a metasemantic view (which is part of an overall theory of meaning attempting to explain the sources or foundations of meaningfulness in general). Rather than proffering explanations of how terms of a particular language compose into meaningful sentences in a way that explains the productivity and learnability of a language, the conceptual role view offers an explanation of that in virtue of which words have the semantic values that they do. If this is right, the conceptual role view is more usefully contrasted (in its appeal to "conceptual roles") with representationalist views about why terms have the meanings they do. Representationalist views stress, in contrast, the way pieces of language stand for things in the (mostly) extralinguistic environment. 
As an intuitive and rough example, a representationalist and conceptual role theorist might agree that the semantic value of the predicate 'is red' is usefully thought of as something like the set of all red things. However, the representationalist will say that this predicate has that semantic value in virtue of standing for the property of redness, whereas a conceptual role theorist would say instead that this predicate has that semantic value in virtue of the conceptual connections to other predicates, such as 'is colored', 'is crimson', 'is orange, is yellow, is blue.... Hence, in what follows, I refer to "conceptual role accounts of meaning" and "conceptual role views" rather than the more customary "conceptual role semantics."

Surprisingly, in spite of its being arguably one of the main theoretical traditions in contemporary philosophy of language, conceptual role views are somewhat difficult to locate in standard metaethical discussions of the meaning of ethical terms. Here, the debate is often conceived as one between cognitivists and noncognitivists, where (in this context) cognitivism is something like the thesis that ethical terms contribute representational content to the sentences in which they figure and hence function semantically primarily to determine conditions of reality that would make those sentences true; and noncognitivism is the view that ethical terms contribute emotive or evaluative content to the sentences in which they figure and so either don't contribute to the sentences' truth conditions or do so only in some trivial and metaphysically noncommittal way.

For example, a cognitivist might say that the predicate 'is wrong' in the sentence "Sexual assault is wrong" represents the property of being wrong, and this is why this sentence is true iff sexual assault has the property of being wrong. (Most who endorse cognitivism think that this or some other simple sentence deploying 'is wrong' is literally true, and so they embrace a form of metaethical realism; however, one can obviously be a cognitivist and antirealist in metaethics by developing a form of error theory or fictionalism.) A noncognitivist would typically reject this, arguing that 'is wrong' is not a term primarily for representing a property but rather a term primarily for expressing one's negative evaluation of something. Hence, noncognitivists often deny that ethical sentences such as "Sexual assault is wrong" are the sorts of sentences properly said to be true or false; or they argue that these sentences have truth conditions in a "deflationary sense" incompatible with a substantive appeal to truth in one's explanation of their meaning. In any case, they think the real action for explaining the meaning of ethical terms lies in the way they serve as vehicles for the expression of emotive or evaluative states of mind rather than the way they represent reality.

If we understand the main debate in metaethics about meaning like this, it's unclear where a view focusing on conceptual roles rather than representational purport or emotive/evaluative expressive function would fit in. With a little care, however, I think we can find versions of the conceptual role view in theories defended by some philosophers inspired by cognitivism and also by other philosophers inspired by noncognitivism. Moreover, I think there's also a third way to conceive of a conceptual role view, one which undermines the stark distinction between cognitivism and noncognitivism (at least as it's commonly understood). ${ }^{1}$

Because of this, in what follows, I want to explain three ways to develop a conceptual role view of meaning in metaethics. First, I'll suggest that there's a way to combine inspiration from noncognitivism with a particular form of the conceptual role view to form a noncognitivist view with distinctive advantages over other noncognitivist views. Second, 
I'll suggest that there's also a way to combine a strong commitment to cognitivism with a different form of the conceptual role view to form a version of cognitivism with distinctive advantages over other cognitivist views. Finally, I argue that another way to think of the conceptual role view in metaethics is as opening up the space for a third way, beyond cognitivism and noncognitivism. But before I turn to those arguments, I begin with brief comments on some relevant distinctions about what determines conceptual roles and what kind of internal connection between ethical thought and action there may be. Then I use these distinctions to explain the three different applications of the conceptual role view.

\section{SOME DISTINCTIONS}

There isn't such a thing as the "conceptual role view about meaning." Rather there is a family of loosely connected views stressing the conceptual role of terms in determining their meaning (usually in contrast to the referential purport of those terms, though we'll see below that those aren't in strict tension). We can begin to understand the contours of this family of views by marking some choice points that distinguish different versions.

Here, without claims to being exhaustive, are four choices any complete conceptual role account of meaning must make (compare Whiting [2006]):

1. Functionalism vs. Normativism: What determines a "conceptual role"? Is it the connections between terms/concepts that a normal user is disposed to make in various circumstances or the ones a normal user ought to make?

2. Globalism vs. Localism about representational content: Do conceptual roles generally determine representational content or is some significant class of conceptual roles nonrepresentational?

3. Solipsistic vs. Social: Is the primary locus of a conceptual role in individuals or linguistic communities?

4. Wide vs. Narrow: Are "language-entry" (from world to mind) and "language-exit" (from mind to world) connections included in a conceptual role? Relatedly, how many conceptual connections are meaning-determining for a term-some "core" set, or all ${ }^{2}$ of them?

In what follows, I focus on 1-2 because (somewhat surprisingly) 3-4 don't seem to matter much to distinguishing the three main ways that I think conceptual roles views might be developed in metaethics. Any complete conceptual role view, though, must settle on answers to all of these questions.

Something else that will be relevant in what follows is what kinds of "internal" connections there may be between ethical thought and action. This is because it is often seen as a benefit of conceptual role views that they can incorporate the supposedly internal connection between ethical thoughts and the actions based on them into an account of the conceptual role of ethical terms. If this works, then it might provide the best explanation of some of the distinctive features of ethical terms in their connections to actions.

As is well known, many different ideas go under the label "internalism" in metaethics, and in philosophy more generally. It would take a whole essay to develop even a highly 
contentious map of the different versions of internalism. In lieu of this, I propose to work with the following crude distinction between:

1. Causal Internalism (vague), the thesis that one's thought that one ought to $\phi$ in $C$ tends in some special way to dispose one's ceteris paribus to $\phi$ whenever in C; and

2. Normative Internalism (vague), the thesis that one's thought that one ought to $\phi$ in $\mathrm{C}$ commits one in some special way to $\phi$ whenever in C.

With those distinctions in hand, let's turn to some possible applications of the conceptual role view in metaethics.

\section{THE CONCEPTUAL ROLE VIEW DEVELOPED AS A FORM OF NONCOGNITIVISM}

The first kind of view is inspired by noncognitivism, which I'm treating here as the view that ethical words contribute emotive or evaluative content rather than representational content to the sentences in which they figure. By drawing on the resources of conceptual role accounts of meaning, there may be room to improve on both traditional and other contemporary views in this vein.

The first step is to argue that the role of a concept is determined by the function it has in our mental economies, its application being caused by and then causing various other applications of concepts. Then, if we assume that words get their meaning from the concepts they express, we get a Functionalist version of the conceptual role view of meaning. (Compare Block [1986], Field [1977], and Harman [1999].)

Next, one mobilizes the metaphor of "directions of fit," whereby some mental states are conceived of as representational in that they "aim" to fit the world and other mental states are conceived of as directive in that they "aim" to get the world to fit them. Then, given a broadly Humean conception of our mental economies, which has it that the cooperation of both kinds of mental states is crucial for motivation to action as well as coordinating our preferences, one can argue that the conceptual role of ethical predicates is action-guiding and preference-coordinating rather than reality-representing. (Compare Bennett [1976].) The argument is roughly that this provides the best explanation of whatever truth there is in the Causal Internalist idea that ethical thoughts have a special causal effect with respect to motivating action and preference.

What results is a picture, according to which some predicates are reality-representing. For instance, ordinary empirical predicates will have, on this view, the conceptual (in this case, functional) role of keeping track of the properties of things in our mostly nonlinguistic external environment. However, ethical predicates are different because of the way their conceptual roles are functionally connected to causing action. In terms of the second choice point above, this means the view is Localist about representational content: The conceptual role of some predicates determines representational content, but this is not true of all predicates, since other predicates (especially ones expressing ethical concepts) don't have representational content on this view.

I'm not sure if anyone endorses a functionalist localist version of the conceptual role view so baldly as I have just presented it, but Blackburn (2006) speaks very favorably about it. ${ }^{3} \mathrm{He}$ contrasts his preferred "non-factualism" about particular areas of thought 
and speech with an approach to semantics that "works in terms of what words and sentences represent." And he suggests that one positive reason in favor of adopting nonfactualism about ethical thought and speech concerns "functional role":

The mental states we voice as we communicate values or moralize to each other seem to be attitudes or practical stances that orientate us towards the world rather than representing any part of it. In a familiar metaphor, they have a different 'direction of fit' with the world, behaving more like desires, whose function is to effect changes in the world rather than beliefs, whose function is to represent the world.

(2006: 245)

And he describes a change in his own view about how best to respond to the Frege-Geach challenge as one moving toward a conceptual role semantics. He describes himself as having proposed, in Blackburn 1988, to modify his theory of the meaning of conditionals by "drawing on conceptual role semantics Harman 1973" and arguing that conditionals get their meaning simply by their role in forcing moves from their antecedents to their consequents, or from the negation of their consequents to the negation of their antecedents (Blackburn 2006: 247).

I take the idea here to be that, rather than suggesting, as some noncognitivists have, that the meaning of a term is the attitude/concept it expresses, we say that the meaning is the conceptual role of whatever attitude/concept is expressed by the term. Then, by allowing for directive rather than representational conceptual roles, we get the view that some terms aren't representations of reality; and by allowing for distinctive pressures on action (e.g., via desire-like directions of fit) we get the positive alternative: Ethical terms are action-guiding rather than world-representing.

In the paper discussing conceptual roles, Blackburn doesn't work through a concrete example, but a quick sketch of one might aid comprehension. I take it his idea is that a predicate such as 'is wrong' means what it does because the concept of something being wrong is connected functionally to other concepts in a complex web of interconnected concepts. It's nontrivial to map this web precisely, but it will include tendencies to make transitions like

- belief that something causes unnecessary pain and suffering $\rightarrow$ belief that it is wrong

- belief that something is right $\rightarrow$ belief that it is not wrong

- belief that something is wrong $\rightarrow$ intention not to do it

- belief that something is wrong $\rightarrow$ preference that others not do it

Is this a version of noncognitivism? Well, as long as these conceptual connections are funded by the role 'is wrong' has in evaluating things rather than what it picks out in reality, it'll be a view that denies that 'is wrong' is a term primarily for representing a property. The idea instead is to view it as a term primarily for expressing one's negative evaluation of something. (Of course, we shouldn't forget that Blackburn [1993; 1998] also pioneered the quasi-realist development of this idea, which hopes to recover talk of moral properties and moral truths via minimalist treatments of 'property' and 'truth'.) In any case, developing the idea in conceptual-role terms promises to carry an advantage over other noncognitivist-inspired views in metaethics: Unlike emotivist views, Blackburn can argue that the inferential connections revealed by Frege-Geach style objections are simply 
special cases of the conceptual (i.e., functional) connections ethical words bear to other words. (Compare Båve [2013] and Warren [2015].) Moreover-and this is rather speculative-unlike prescriptivists like Hare and perhaps even fellow expressivists like Gibbard, Blackburn's variegated functionalism is more flexible in that the functional role of ethical concepts doesn't always have to be spelled out in terms of prescriptions or plans. So it looks like it's going to be able to handle cases where it is implausible that ethical claims are "universally prescriptive" or "plan-laden" in any plausible sense of these notions.

As I see things, to make this fly, Blackburn needs something plausible to say about how the conceptual roles (as he conceives them) of ethical terms determine their contribution to the truth-conditions of the sentences in which they figure. Of course, as a quasi-realist, he'll want some kind of deflationism about truth, so that assigning truth conditions to a sentence in the way we do in compositional semantics is not viewed as ascribing it representational content. But even so, if our functionalism is too loose, allowing in all sorts of dispositional connections between various attitudes, we risk conceptual roles including extraneous stuff not plausibly thought to be determinative of the sort of semantic content that is supposed to determine truth conditions. So we'll want some plausible story about a term's "core" functional role, which allows us to distinguish in a non-question-begging way which functional connections are part of the meaning of ethical terms and which are extrasemantic (e.g., because of deriving from pragmatic goals or from customs of politeness, etc.). Also, a view like this one will face the sorts of challenges that have been posed by Kripke (1982) to the idea that naturalistically describable functional roles might determine semantic content. (For ideas on how to preserve noncognitivism within a broadly normative conception of meaning, which might provide a way to respond to this objection, see Price [2011] and Gibbard [2012].)

\section{THE CONCEPTUAL ROLE VIEW DEVELOPED AS A FORM OF COGNITIVISM}

A flatfooted representationalist account of meaning might say that predicates mean what they mean solely in virtue of what properties, in reality, they stand for. We know this can't be right because two different terms can stand for the same property in reality, even necessarily so, without being synonymous-'closed triangular figure' and 'closed trilateral figure' have different meanings (witness the fact that someone might understand one but not the other). As a result, many have been tempted to say that the meaning of terms is determined by something like their conventionalized role in our conceptually imbued practices. On this view, grasping a term's meaning amounts to something like cottoning onto enough of the core rules governing its use. This is one thing that might be called a term's "conceptual role."

Peacocke (1995) argued, however, that going this route is compatible with the view that concepts stand for things in reality or that the terms expressing concepts have referential purport as part of their meaning. For one might think that part of the job of terms is to express concepts, and part of the role of these concepts is to stand for something in reality (whether instantiated or not). If that's right, then although we might focus in the first instance on explaining the way one ought to use a term, this explanation could be argued to determine what in reality this term stands for. For example, a kind of conceptual role view about 'is red' might say that this means what it means because of its conceptual 
connection to other predicates such as 'is colored' and 'is crimson', but that this conceptual role determines what in reality the term stands for: the property of redness.

Moreover, once we had that in the picture, we could mobilize relatively standard accounts of how different terms standing for different things can, along with logical form, determine the conditions under which declarative sentences with those terms are true. Accordingly, it seems that embracing a conceptual role account of meaning is perfectly consistent with a representationalist understanding of truth-conditional semantics.

Whether that is the best understanding of truth-conditional semantics is, of course, a controversial issue. But I bring this possibility up here in order to explain how this line of thought opens up space for an account of the meaning of ethical terms inspired by traditional realist forms of cognitivism but also with improved resources for addressing one of the standard worries about those views.

The worry is that construing an ethical predicate such as 'is wrong' as standing for some property (such as being wrong) makes it hard to account for an apparent difference between the practical justificatory force of ethical claims and other claims. Roughly put, this difference is that ethical terms are mainly for evaluating things in a way that we take to bear pretty directly on which actions to perform, whereas other words seem to be mainly for describing things in a way that seems to bear only indirectly on which actions to perform. How could the term 'is wrong', when it's presumed to stand for being wrong, carry this extra justificatory "oomph," compared with a non-ethical term such as is frequent', which is presumed to stand for being frequent? For, if someone thinks an action is frequent, nothing follows about what they're justified in doing, whereas someone who thinks that an action is wrong is prima facie justified in not performing it. (As we'll see, this is clearly related to the Normative Internalist thesis mentioned above.)

Something like this line of thought forces some cognitivists to say that ethical properties are sui generis precisely in the sense that their attribution carries special practical justificatory force. However, a Peacocke-inspired conceptual role account of the meaning of ethical terms would have a different response: The practical justificatory force of the attribution of ethical properties could be part of their conceptual role, in the sense that it's one of the rules of use one must grasp (at least implicitly) in order to count as understanding their meaning; it doesn't have to be a sui generis feature of the things in reality that they refer to. In terms of the distinction gestured at above, this amounts to an argument that a conceptual role view of meaning might, when applied to ethical terms, offer a better explanation of whatever truth there is in Normative Internalism than competing cognitivist views.

It's possible to develop this idea in a functionalist way by arguing that ethical thoughts tend to cause other thoughts about actions being justified or thoughts about practical commitments. However, I think a normativist development better captures the normative version of internalism, which isn't about what thoughts someone tends to have but rather what actions one is committed to in virtue of having ethical thoughts. The idea is that part of the conceptual role of ethical terms is their power to commit one who deploys them to act in various ways. Whether one tends to be motivated to so act is a separate question.

Should the view be Globalist or Localist? There's room to go either way on this choice point, though there's pressure to develop the view in Globalist ways: Insofar as the view is inspired by a version of cognitivism, a normativist conceptual role account of the 
meaning of ethical terms will need some justification for saying that ethical predicates have (or determine) representational content. One good justification would be that all predicates are assumed to represent properties. This is the globalist position. (It would be open, however, to someone developing this cognitivist view of ethical terms to argue that ethical terms are representational but some other terms are not. For example, there is more purely, narrowly linguistic evidence that epistemic modals and probability operators behave nonrepresentationally. (Compare Yalcin [2007; 2011].) So, one could be antirepresentationalist about them but not about ethical terms.

Again, I don't know if anyone develops a Normativist, Globalist application of the conceptual role view to ethical terms as baldly as I just have here, but Wedgwood (2001; 2007) has developed a metaethical view in this general vein. He argues that an account of the meaning of any term and so ipso facto ethical terms should explain "what it is for someone to understand the term - that is, to be a competent user of the term" (2001: 5). Drawing on Peacocke (1987; 1995), then, he develops this idea of competence in terms of dispositions to follow the basic rules of rationality governing a term's use: "According to the version of conceptual role semantics that I wish to develop, the meaning of a term is given by the basic rules of rationality governing its use" (Wedgwood 2001: 6). What makes them "basic" for him is that "the rationality of following these rules, and the irrationality of violating them, must not be due merely to the availability of some independent justification of these rules" (Wedgwood 2001: 8), presumably ruling out non-semantic justifications of pragmatics, politeness, etc. These comments suggest a normativist understanding of the conceptual role-indeed, one with resources for distinguishing between all of the various connections that may stand between concepts and the "core" ones determinative of meaning.

As Wedgwood notes, the conceptual role of any term will be complex in ways that are difficult to map succinctly, and even his summary treatment of 'better' and 'ought' have complexities I won't cover here. But it may aid comprehension to sketch the basic idea with these two terms. Wedgwood (2001) argues that thinking that some course of action is, all things considered, better than another commits one to having a preference for that course of action over the other. So, he thinks a core rule of rationality governing "better" is that one make transitions in thought of the form:

belief that $x$ is all things considered better than $y$ for me to do $\rightarrow$ preference for doing $x$ over doing $y$.

Similarly, Wedgwood (2007: chapter 4) argues that thinking that $p$ ought to be true (in the way characteristic of all things considered deliberative normative thought for oneself) commits one to making the truth of $p$ part of one's ideal plan about what to do. So, that means that he thinks a core rule of rationality governing 'ought' is that one make transitions in thought of the form:

belief that $p$ ought (all things considered, and relevantly to my practical deliberation) to be true $\rightarrow$ planning for $p$ to be true.

So far, that sounds like something that could be incorporated into a noncognitivist version of the conceptual role view if we traded out Blackburn's functionalism for a normativist 
conception of these transitions. However, Wedgwood clearly intends his view as a version of cognitivism.

In the earlier paper, he proposes to simply "....assume that every moral term has the function of standing for a property or relation," which amounts to assuming "...that cognitivism is correct, and that the meaning of moral terms is straight-forwardly truthconditional" (2007: 6). In the book (Wedgwood 2007), he spends a chapter arguing against noncognitivist views, including sophisticated expressivist views such as Blackburn (1998) and Gibbard (2003). I don't have space here to present his argument in full, but it turns on the idea that there are preferences and plans that are correct in some more "external" sense than being determined by coherence with all of one's other beliefs, preferences, and plans (even when these are improved by further information and more careful reflection). Because of this, he thinks our normative thought and discourse is implicitly committed (in ways an expressivist cannot capture) to there being some property or relation that betterness- and ought-judgments are about. This will be the property or relation making the core set rules governing the use of these terms valid and complete. Insisting that the conceptual roles of predicate terms determine such properties or relations is what he takes to secure his commitment to cognitivism. Moreover, he argues that the availability of this package undermines any advantage noncognitivists might have thought they win from the internal justificatory connection between ethical concepts and action. He writes "...the idea that the meaning of moral terms is given by their role in practical reasoning is fully available to cognitivists, and so lends no support to noncognitivism" (Wedgwood 2001: 18).

Once we're working with a cognitivist conception of conceptual roles, however, there's also a more general reason to think ethical terms add representational content to the sentences in which they figure: If you thought that a term expresses a concept iff it affects the truth conditions of sentences in which it figures, and you had a representationalist conception of truth-conditions, then you might think that all semantically contributing terms should be treated representationally. In other words, in order to have a semantic value, a term would have to stand for something (though what it stands for is determined by its conceptual role). This reasoning seems to be in the background of what Wedgwood says regarding the semantics of 'ought': "Within the semantic framework that I am assuming here, the semantic value of the concept ' $O<A$, $t>$ ' will in effect be a certain property of propositions - presumably, a relational property that propositions have in virtue of some relation in which they stand to the agent $A$ at the time $t$ " (2007: 99).

Because he thinks some ethical statements are true and so successfully represent reality, Wedgwood's view faces the metaphysical challenges of other realist views: Show that the properties represented by ethical words are natural or explain why it's ok in this case (but not in most other cases) to countenance the existence of non-natural properties. Also, the conceptual role he gives for 'ought' treats it as a propositional operator, roughly akin to a necessity operator. Hence, his globalism leads him to view this as representing a property had by propositions. This commits the moral realist going this route not only to properties of goodness and wrongness but also to properties propositions have when they are correctly incorporated into plans. One might reasonably be more skeptical of such "logical" properties of propositions than of more ordinary properties of actions. 


\section{THE CONCEPTUAL ROLE VIEW AS A THIRD OPTION}

The labels "cognitivism" and "noncognitivism" suggest there is no third way, but the substance of the views (at least as defined above, which I think captures one prominent way these labels are used in metaethics) doesn't rule out a view according to which ethical words contribute neither representational content nor emotive/evaluative content to the sentences in which they figure. To see this, notice that a common view taken about terms such as the copula ('is'), articles ('a', 'the'), logical connectives ('not', 'if'), and epistemic operators ('probably') is that they don't stand for things in reality, but neither do they carry emotive/evaluative content. Rather, they do various other jobs in our sentences, such as linking together other words with representational and/or evaluative content and qualifying, situating, or displacing some embedded piece of representational content. The third conceptual role view I discuss here takes inspiration from this model to suggest that the conceptual role of at least some ethical terms is to perform one of these other jobs.

It's not clear how to think of these "other jobs" in general, but one significant distinction is between broadly "logical" and "non-logical" terms. In this vein, with a very broad conception of the "logical," Brandom (2008) argues that we should recognize a distinction between terms directly involved in first-order conceptualization of reality and what to do in it (roughly, what we convey with simple declarative and volitive/imperative sentences) and terms whose job it is to "make explicit" the inferential commitments implicitly carried by first-order thought and discourse. (Compare also Kant [1997: 209], Frege [1879: 13], and Sellars [1958].) On Brandom's way of working out this view, terms in this latter class have a distinctively second-order conceptual role in their job of articulating inference rules. These are not descriptions of how people happen to infer but normative claims about how people ought to infer. As such, this suggests a Normativist version of the conceptual role view (with Wedgwood, against Blackburn). However (against Wedgwood, with Blackburn), it is Localist about representational content: Not all words' conceptual roles determine representational contents. Some words are treated as "metaconceptual" devices for talking about the inferential connections between other words.

This is most plausible when applied to ethical words that are also operator-like. In Chrisman (2016), I focus on 'ought', which is plausibly construed as functioning semantically as an intensional (and more specifically, modal) operator. (Compare Castañeda's [1975] treatment of 'ought' as a practical necessity operator and Sellars' [1958: 282; 1968: chapter 7] suggestion that its content is partly determined by its distinguished role in practical reasoning.) According to the argument I develop, the conceptual role of this word is like other intensional operators, such as 'might' or 'probably', in that its addition to a sentence shifts something about how the sentence puts forward some embedded piece of content. For example, "Paula might be home," is not treated as representing Paula (or anyone else, such as her counterparts in some epistemically accessible possible worlds) as having some property but rather is conceived as a vehicle for putting forward a more basic piece of representational content (Paula is at home) as an epistemically open possibility, roughly something not ruled out by the beliefs held to be commonly agreed upon in an ongoing conversation.

Similarly, then, we might think that "Paula ought to be home" does not represent Paula (or anyone else, such as her counterparts in all normatively accessible worlds) as having 
some property, but rather conceive of this sentence as a vehicle for putting forward a more basic piece of content (Paula is at home) as a normative necessity, roughly something that is, so to speak, ruled in by the beliefs and norms/prescriptions held to be commonly agreed upon in an ongoing conversation.

In this way, we get a version of the conceptual role view that treats the conceptual role of some terms as distinctive from representational terms, not in their link to emotive/evaluative content but rather in their metaconceptual function. Because, on this view, the words with metaconceptual function do not add representational content to the sentences in which they figure, this view might be classed as a form of antirealism about 'ought', avoiding many ontological worries associated with realist forms of cognitivism. However, because this metaconceptual function is very specific, the hope is that the view will have an easier time than the noncognitivist-inspired conceptual role view discussed above at explaining how these words affect the truth-conditional content of the sentences in which they figure. Moreover, there should be less of a worry about how to cordon off apparently nonsemantic connections between the concepts expressed by these terms and other concepts.

In chapter 5 of Chrisman (2016), I argue that a modification of the standard truthconditional semantics for modal operators can be developed to predict contents for many of the diverse flavors of ought-sentences we witness in natural language. This semantic account is incomplete, but insofar as it makes plausible predictions in a compositionally tractable way, I think that represents an advance over expressivist views that would assign contents to ought-sentences in some nonstandard way. In my view, developing a plausible rule for predicting truth conditions for arbitrary ought-sentences leaves open the crucial metasemantic issue of what it is in virtue of which these sentences have the truth conditions that they do. I then argue in chapter 6 that a broadly inferentialist account of meaning has resources to explain the conceptual role of 'ought' in a way that grounds its semantic content in neither a word-world representation relation nor a word-mind expression relation. This form of antirealism assimilates 'ought' more with an antirealist view of the meaning of necessity modals than with an antirealist view of the meaning of emotive/evaluative terms.

Where does a view like this stand with respect to both Causal and Normative Internalisms? Regarding the former, there is nothing to prevent someone pursuing this kind of view of the meaning of a term such as 'ought' to argue that there is a causal-functional connection between applications of this words and motivations to act. For my part, I think such a connection is plausible only in a very small percentage of the cases where we use 'ought' (roughly, whenever it's plausibly interpreted as all-things-considered and about the speaker's own future actions), so I think it's implausible to think this is a "core" element of the term's meaning, but there's nothing in the basic contours of the view that rules out develop a specific version of it with this feature. Much more plausible, I think, is some form of the normative internalist thesis. And the normativist development of a conceptual role view of 'ought' provides ample resources to capture whatever truth there is in that thesis.

In the context of metaethics, there are two important challenges faced by views like this one. First, it is not clear that they can be extended to cover ethical (or normative) terms considered quite generally. The word 'ought' might be one of the core normative terms, but semantically it is an intensional operator, and that's what supports the idea that its conceptual role is metaconceptual. The term 'is wrong', however, is an ordinary 
predicate. Sure, we sometimes think that what makes such words ethical (or normative) is that they bear directly on what one ought to do, but significant work still needs to be done to show that the Brandom-inspired conceptual-role view about 'ought' can be developed into a full metaethical view about the meaning of ethical words (see Chrisman [2016: chapter 7] where this is discussed in more detail). Second, it is not clear what it is in virtue of which the word 'ought' (and other so-called "metaconceptual" words) has the second-order conceptual role that I've suggested that it has. In contrast to Blackburn, a defender of this view cannot locate this in natural facts about how we happen to use these words, as this version of the conceptual role view is normativist rather than functionalist; and in contrast to Wedgwood, a defender of this view cannot locate this in the bits of reality that these words stand for, as its localism is designed to avoid commitment to thinking these words stand for things in reality. So, what kind of fact is it that 'ought' has a second-order or "metaconceptual" conceptual role? A full defense of this view requires a convincing answer to this difficult question. It's one that arises when we think meaning is, in some important sense, normative, but are inclined to think "the normative" is not some special realm of reality. What happens when we turn a normativist conceptual role version of antirealism about normative terms on itself?

\section{CONCLUSION}

At the beginning of this essay, I said that it's unclear where conceptual role views about meaning apply amongst metaethical theories about the meaning of ethical terms. I think that's because the basic idea behind conceptual role views can be developed in several interesting ways. In some of Blackburn's work, we see a noncogntivist-inspired form of the view. It's a Functionalist and Localist version of the conceptual role view, explaining the meaning of ethical words in terms of the way the concepts they express serve to direct action and, as such, do not have representational content. By contrast, Wedgwood develops a cognitivist-inspired application of the conceptual role view to ethical terms. It appears to be a Normativist and Globalist version of the view, explaining the meaning of ethical words in terms of the core set of rules governing the practical reasoning of one deploying the concepts that they express, which he takes to determine the property that they denote. In my work, I've been inspired by Wedgwood's Normativism and Blackburn's Localism. By drawing on Brandom's idea to distinguish terms with a secondorder metaconceptual role from terms with first-order descriptive function in our conceptually imbued practices, I think we might develop an explanation of the meaning of at least some core ethical terms that is not obviously cognitivist nor noncognitivist (but antirealist in a more pragmatist sort of way).

Above, I mentioned two further questions any conceptual role account of meaning must answer: Is the primary locus of conceptual role in individuals or linguistic communities? And, are "language-entry" (from world to mind) and "language-exit" (from mind to world) connections included in the conceptual role? I think all of the views I have discussed here are compatible with either answer to both questions.

In the first case, this is because, for all we have said about what conceptual roles might be like, we have said very little about what grounds them or where they come from. Many in the conceptual role tradition stress the way language is a social phenomenon, 
which inclines those who view conceptual roles as a key to explaining linguistic meaning to favor a more social answer to the first question. However, one could also think that the psychology of individual agents and its biological development takes pride of place in the explanation of the possibility of content; and if one does, it can begin to seem like the sociality of linguistic practice depends on the prior existence of a more solipsistic kind of content. The important point here is that it is a general issue for any conceptual role view and not something that seems to bear specifically on conceptual role views in metaethics.

The second question might seem to have more bearing on metaethics, because many in the conceptual role tradition have thought that the conceptual role of ethical terms must have something to do with action, which is the paradigmatic "language-exit," where our minds, so to speak, touch the world. However, for any "wide" conceptual role view (including language-exit connections as part of conceptual roles), it seems to me that we could imagine an analogous "narrow" conceptual role view that stops the connection at the point of an intention or volition. So, again, this seems to be an issue that cuts across various developments of the conceptual role view in metaethics.

\section{NOTES}

1. Of course, one could simply define noncognitivism as the denial of cognitivism, in which case conceptual role views would have to fall on one side or the other. However, that way of conceiving of noncognitivism doesn't fit well with antirepresentationalist views witnessed in areas other than ethics. Some philosophers think, for example, that epistemic modals, probability operators, the truth predicate, etc. are not devices of representation. However, it's weird to refer to them as noncognitivists about these things, as they would insist that thought involving the relevant concepts is part of cognition rather than affect, and they generally think it can constitute knowledge.

2. This is related to a broader issue in the philosophy of language about holism vs. atomism about meanings. Predictably, no one in favor of a conceptual-role view is an atomist, in the sense of holding that a word/concept has content all on its own, as something that then gets added atomistically to form the compound contents of phrases and sentences. However, there are differing opinions about whether it is possible to draw some non-arbitrary line between the connections language users tend or ought to track that are part of specifically semantic competence with words and those that are part of wider understanding of the world. If, following Quine, one thinks there is no sharp line between analytic and synthetic truths, then one will think it difficult to draw a sharp line between the "conceptual connections" and the "substantive" connections between various propositions. However, most conceptual role theorists will be happy to recognize that some connections are more central to a term's meaning than others.

3. See also Köhler (2014, forthcoming) for someone who endorses a view like this one. Gibbard (2003) develops a sophisticated and noncognitivism-friendly account of the contents of the mental states expressed by normative sentences. He suggests that this account, which construes all normative thought as "plan-laden," is consistent with a naturalistic account of the role normative thoughts play in our mental economies (especially in their connection to action). (See especially pp. 154 and 195.) If we take these plan-laden thoughts (and the sentences expressing them) to have those contents in virtue of playing the relevant role in guiding action, then I think we get another version of the functionalist kind of conceptual role view sketched above. It's somewhat more restrictive about the role played by normative thought than I think Blackburn wants to be, but it still would explain meaning in terms of functional role. However, Gibbard also suggests there that his view of the contents of the mental states expressed by normative sentences is consistent with the view that meaning is normative, which in his scheme would mean that the thoughts expressed by normative sentences cannot be identified in purely naturalistic terms. (This idea is 
explored in much more detail in Gibbard [2012].) Going this way would constitute a departure from the functionalist kind of conceptual role view sketched above.

\section{ACKNOWLEDGMENTS}

For helpful feedback on this chapter, I'd like to thank Max Barkhausen, Samuel Dishaw, James Fritz, Sebastian Köhler, Michael Ridge, Silvan Wittwer, and the editors of this handbook.

\section{RELATED TOPICS}

Chapter 5, "Expressivism"; Chapter 12, "Deontic Modals"; Chapter 18, "Cognitivism and Non-Cognitivism"; Chapter 33, "Metasemantics and Metaethics"; Chapter 37, "Pragmatism and Metaethics"; and Chapter 40, "Quasi-realism."

\section{REFERENCES}

Båve, A. (2013) "Compositional Semantics for Expressivists," The Philosophical Quarterly 63 (253): 633-59. Bennett, J. (1976) Linguistic Behaviour, Cambridge: Cambridge University Press.

Blackburn, S. (1993) Essays in Quasi-Realism, New York: Oxford University Press.

-. (1998) Ruling Passions: A Theory of Practical Reasoning, New York: Oxford University Press.

-. (2006) "The Semantics of Non-Factualism," in The Blackwell Guide to the Philosophy of Language, Devitt, M. and Hanley, R. (eds.), Oxford: Blackwell, pp. 244-52.

Block, N. (1986) "Advertisement for a Semantics for Psychology," Midwest Studies in Philosophy 10: 615-78. Brandom, R. (2008) Between Saying and Doing, Oxford; New York: Oxford University Press.

Castañeda, H-N. (1975) Thinking and Doing: The Philosophical Foundations of Institutions. Berlin: Springer.

Chrisman, M. (2016) The Meaning of 'Ought': Beyond Descriptivism and Expressivism in Metaethics, New York: Oxford University Press.

Field, H. (1977) “Logic, Meaning and Conceptual Role," Journal of Philosophy 69: 379-409.

Frege, G. (1879) Begriffsschrift, eine der arithmetischen nachgebildete Formelsprache des reinen Denkens. Halle a/S.: L. Nebert.

Gibbard, A. (2003) Thinking How to Live, Cambridge, MA: Harvard University Press.

-. (2012) Meaning and Normativity, Oxford: Oxford University Press.

Harman, G. (1999) Reasoning, Meaning and Mind, Oxford: Oxford University Press.

Kant, I. (1997) Kritik der reinen Vernunft, Guyer, P. and Wood, A. (trans./eds.) Cambridge: Cambridge University Press.

Köhler, S. (forthcoming) "Expressivism, Belief, and All That," Journal of Philosophy, forthcoming.

Köhler, S. (2014) Beyond Frege-Geach - Neglected Challenges for Expressivism, Ph.D. Thesis, University of Edinburgh.

Kripke, S. (1982) Wittgenstein on Rules and Private Language: An Elementary Exposition, Cambridge, MA: Harvard University Press.

Peacocke, C. (1987) “Understanding Logical Constants: A Realist's Account," Proceedings of the British Academy 73: 153-99.

-. (1995) A Study of Concepts, Cambridge, MA: MIT Press.

Price, H. (2011) "Expressivism for Two Voices," in Pragmatism, Science and Naturalism, Knowles, J., and Rydenfelt, H. (eds.), Frankfurt am Main: Peter Lang, pp. 87-113.

Sellars, W. (1958) “Counterfactuals, Dispositions, and the Causal Modalities," in Minnesota Studies in the Philosophy of Science, Volume II, Feigl, H., Scriven, M., and Maxwell, G. (eds.), Minneapolis: University of Minnesota Press, pp. 225-308. 
-. (1968) Science and Metaphysics: Variations on Kantian Themes, London: Routledge and Kegan Paul.

Warren, M. (2015) "Inferentialism and the Frege Geach Problem," Philosophical Studies 172 (11): 2859-85.

Wedgwood, R. (2001) “Conceptual Role Semantics for Moral Terms," Philosophical Review 110 (1): 1-30.

-. (2007) The Nature of Normativity, Oxford; New York: Oxford University Press.

Whiting, D. (2006) “Conceptual Role Semantics," Internet Encyclopedia of Philosophy. http://www.iep. utm.edu/.

Yalcin, S. (2007) “Epistemic Modals," Mind 116 (464): 983-1026.

-. (2011) "Nonfactualism about Epistemic Modality," in Epistemic Modality, Egan, A. and Weatherson, B. (eds.), New York: Oxford University Press: pp. 295-332. 